\title{
Effect of Self-Management Support Program on Improving Knowledge and Practices of Patients with Diabetic Foot
}

\author{
Fatma Mohamed Abdelhamid ${ }^{1}$, Nadia Mohamed Taha ${ }^{2}$, \\ Mohamed N. EL-Khashab ${ }^{3}$ and Elham Hamad Mohamed ${ }^{4}$ \\ ${ }^{1}$ B.Sc. Nursing, Faculty of Nursing, Zagazig University, Egypt. \\ ${ }^{2}$ Medical Surgical Nursing, Faculty of Nursing, Zagazig University, Egypt. \\ ${ }^{3}$ Tropical Medicine Department, Faculty of Medicine, Zagazig University,Egypt. \\ ${ }^{4}$ Medical Surgical Nursing, Faculty of Nursing, Zagazig University, Egypt.
}

Corresponding Author Fatma Mohamed Abdelhamid

Mobile: 01149696971

E mail:

Ommena515@yahoo. com

Key words: Diabetic foot care behaviors, Selfreported practice, Selfmanagement
Background and study aim: Diabetes is a self managed disease and the participation of the individual, health care team and his family is very essential in managing the disease and preventing its complications. The aim of study was to evaluate the effectiveness of a self-management support program on improving Knowledge and practices of patients with diabetes mellitus at Zagazig University Hospital.

Subjects and Methods: A quasi experimental research design was used in this study. A purposive sample of 70 patients with diabetic foot patients were randomly assigned to either the control $(n=35)$ or the study $(n=35)$ group using matched criteria of foot ulcer history and foot problems. Three tools were used for collection of data, patient's assessment questionnaire, questionnaire about patient knowledge about diabetes mellitus and foot care and self reported practice questionnaire.

Results: The study finding revealed that sixty $(60.0 \%)$ of patients in the study and control groups were males with more than 40 years of age with Mean \pm SD $(52.7 \pm 8.8$

\section{INTRODUCTION}

Diabetes is one of the main health problems in all countries. World Health Organization (WHO) mentioned it as a silent epidemic [1]. Diabetes is a group of metabolic diseases characterized by hyperglycemia resulting from defects in insulin secretion, insulin action, or both. The chronic hyperglycemia of diabetes is associated with long-term damage, dysfunction, and failure of different organs, especially the eyes, kidneys, nerves, heart, and blood vessels [2]. Diabetic foot ulcers (DFUs) are and $53.5 \pm 7.8$ respectively), there was statistical significant relationship between patient knowledge and practice where more than three quarters $(89.6 \%)$ of patients who had unsatisfactory knowledge had inadequate practice. Also there was positive correlation between foot care score and knowledge score and practice score.

Conclusion: The self-management support program showed an improvement in patients' knowledge which reflected an improvement on their practice and diabetic foot care behaviors in post phase. It is Recommended to increase awareness and prevent the diabetic foot and its complications by apply nursing intervention programs regarding importance of foot care and to impart knowledge on foot care, use media to motivate diabetic patient for monthly diabetic clinic visiting, use media to increase awareness about the diabetic foot, continues follow up for patients who is suffering from the diabetic foot and increase distributing free handbooks that are specific for diabetes in the public places.

related with weighty morbidity and mortality, yet they are one of utmost avoidable long-term problems of DM [3]. Timely diagnosis and demonstration to hospital for rapid treatment of DFU is proficient of decreasing the weighty morbidity and mortality linked with this illness. Early revealing of peripheral neuropathy and patient's learning concerning foot care and footwear is essential in decreasing danger of any harm which could cause ulcer formation (4). Additionally, humble foot care manners is known to increase the

Abdelhamid et al., Afro-Egypt J Infect Endem Dis 2019; 9(1):46-57

https://aeji.journals.ekb.eg/

http://mis.zu.edu.eg/ajied/home.aspx 
hazard of ulcerations, amputations and mortality [3].

The occurrence of diabetes is growing; consistent with epidemiological studies proceeded during the past decade, the total quantity of persons with diabetes is expected to rise from 171 million in 2000 to 366 million in 2030 [3]. On a global scale, the prevalence of diabetes has continued to increase steadily, reaching $8.8 \%$ between adults of 20-79 years old in 2015 [5].

\section{Significance of the study:}

One of the most disabling complications of DM is Diabetic Foot Ulcers (DFU) which affect 15$25 \%$ of diabetic patients and may lead to gangrene, infection and/or foot amputation. These complications can lead to severe adverse effects including a high financial burden, physical disability, depression, low quality of life and high mortality. Since effective long term treatment of DFU is difficult, costly and time consuming and since ulcers often reoccur even after healing, their prevention is very important. It is, therefore, essential to develop SM support programs to encourage diabetic patients to improve their knowledge and practices toward diabetes and their diabetic foot.

\section{SUBJECTS AND METHODS}

A quasi experimental research design was utilized to conduct the study. The present study was conducted in diabetic outpatient clinic and diabetic foot outpatient clinic at Zagazig University Hospitals three days per week.

\section{Subjects:}

A purposive sample of 70 patients with diabetic foot. The subjects were randomly assigned to either the control $(n=35)$ or the patients $(n=35)$ group using matched criteria of foot ulcer history and foot problems and fulfill the following criteria:

\section{Inclusion criteria}

1-The subjects included in the study were aged between 18 and 65 years old.

2-Ability to contact by telephone.

3 -Agree to participate in the study.

\section{Exclusion Criteria:}

Subjects were excluded from the study if they developed severe complications including severe diabetic retinopathy, severe vision or hearing problems or other disabilities and joint problems, or otherwise became unable to perform foot care independently.

\section{Tools for data collection:}

Three tools were used for data collection :

Tool I: Patient's assessment questionnaire: this tool was developed by the researcher composed of three parts:

Part I: Included the following:demographic characteristics of patients: it consisted of 6 closed ended questions include age, sex, level of education, job related to health, smoking, marital status and follow up(regular, irregular).

Part II: Included history of diabetes onset and management among diabetic patients, it included the following: Duration of diabetes mellitus, random blood glucose level (routine investigation from patient sheet) and treatment of diabetes .

Part III: Data related to feet problems and related education among diabetic patients $; 10$ questions about feet symptoms such as( tingling, spasm, decreased sensation),feet signs such as( ulcers, bleeding, callosity), had training in foot care and want to educate about feet care.

\section{The Scoring system:}

This patient assessment tool consisted of open ended questions and closed ended questions scored through yes $=1$ no $=0$ and calculate of range, mean, median and standard deviation.

Tool II- Questionnaire about prior patient knowledge about diabetes mellitus and foot care, classified into two parts:

Part I: consisted of 9 questions for patient knowledge about diabetes and foot care. It was formed of multiple choice and open ended questions. For example definition of diabetes, causes, symptoms complications, prevention from complication, causes of hypoglycemia, symptoms of hypoglycemia, proper diet, no of meals.

Part II: consisted of 5 questions about foot care(importance, right method for diabetic foot care, right method to cut toes nail, wound risks, delay wound healing).

\section{Total Scoring system:}

Knowledge: For the knowledge items, a correct response was scored 1 and the incorrect zero. For each area of knowledge, the scores of the items were summed-up and the total divided by the number of the items, giving a mean score. This 
score was converted into a percent score. Knowledge was considered satisfactory if the percent score was $50 \%$ or more and unsatisfactory if less than $50 \%$.

Tool III: Self reported practice Questionnaire : This tool Consisted of five parts determined the patient's practices related to DM among diabetic patients.

Part I: included practice during hypoglycemia and carry DM card.

Part II: included medication use (take drug on time, change dose).

Part III: included personal hygiene (follow personal hygiene, how to care your eyes, regularly visiting ophthalmologist, regularly visiting dentist, number of bathing).

Part IV: included physical exercise(following certain physical exercise (walking), regular practicing physical exercise.

Part V: included patient's practice toward diet (following diabetic diet regimen, following diabetic diet since discovering diabetes).

\section{Self reported practice :}

The items reported to be done correctly were scored "1" and the items not done were scored " 0 ". For each area, the scores of the items were summed-up and the total divided by the number of the items, giving a mean score for the part. These scores were converted into percent scores. The practice was considered adequate if the percent score was $60 \%$ or more and inadequate if less than $60 \%$ based on data analysis.

\section{Self management support program :}

The program principles were to encourage diabetic patients to achieve the desired diabetic foot care behavior effectively. Field work of this study was executed in 10 months from the beginning of June 2017 to the end of March, 2018.

\section{Content validity and Reliability :}

During this phase, the researcher prepared the data collection tools in their preliminary form. They were then presented to a panel of three experts for face and content validation. These included two lecturers in Medical Surgical Nursing, and one professor from Faculty of Medicine, Zagazig University, who revised the tools for clarity, relevance, comprehensiveness, understanding, and ease for implementation and according to their opinion minor modification were applied.

\section{Reliability :}

The reliability test was done for tools by using Cronbach's Alpha test was 0.891. This showed that the reliability coefficients are in the high values.

Field work of this study was executed in 10 months from the beginning of June 2017 to the end of March, 2018. The period of data collection was divided into the following:

The researcher started by introducing herself to the patient, the aim of the study and the component of the tools were explained to the patients at the beginning of data collection, they were assured that the information collected would be treated confidentially and that it would be used only for the purpose of the study (oral consent was taken from the patients).

The researcher visited the diabetic out-patient clinic two days per week during morning shift 9: $\mathrm{AM}$ to 12:MD. The patient filled the written questionnaire in the presence of the researcher or it was filled by the researcher for illiterate patient, the time needed for completing the patient's assessment tool, questionnaire sheet about patient knowledge and foot care scale(pre-post test) was about 45 minutes for each patient. The patients were interviewed in the outpatient clinic weekly at time of follow up and followed by telephone to set goal and action plan.

\section{Statistical Design:}

Data entry and statistical analysis were done using SPSS 20.0 statistical software package. Data were presented using descriptive statistics in the form of frequencies and percentages for qualitative variables, and means and standard deviations and medians for quantitative variables. Cronbach alpha coefficient was calculated to assess the reliability of the developed scale through their internal consistency. Qualitative categorical variables were compared using chi-square test. Whenever the expected values in one or more of the cells in a $2 \times 2$ tables was less than 5, Fisher exact test was used instead. In larger than $2 \times 2$ cross-tables, no test could be applied whenever the expected value in $10 \%$ or more of the cells was less than 5. Spearman rank correlation was used for assessment of the inter-relationships among quantitative variables and ranked ones. In order to identify the independent predictors of the scores of knowledge and practice, multiple linear regression analysis was used and analysis of variance for the full regression models done. Statistical significance was considered at p-value $<0.05$. 


\section{RESULTS}

The first part of our results illustrated demographic features of diabetic patients in the investigated and control groups. More than half $(51.4 \& 60.0 \%)$ of patients in the observed and control groups were males greater than 40 years of age with mean $\pm \mathrm{SD}(52.7 \pm 8.8$ and $53.5 \pm 7.8$ respectively). The highest percentages of investigated and control group (77.1\% and $94.3 \%$ respectively) were married. As regard to educational level, $62.9 \%$ of patients in study group had basic education and $45.7 \%$ of patients control group had basic education. $62.9 \%$ of the observed patients \& $45.7 \%$ of the control had basic, intermediate education Almost, all of patients (study and control groups) $97.1 \% \& 100.0 \%$ respectively had job not related to health. $85.7 \%$ \& $62.9 \%$ respectively in the study and control groups were non-smokers (Table 1).

The second part of our results was concerned with medical history showed that, $62.9 \%$ \& $60.0 \%$ respectively, of patients in the study and control groups had blood glucose level +140 $\mathrm{mg} / \mathrm{dl}$ with Mean $\pm \mathrm{SD} 157.9 \pm 41.0 \& 167.9 \pm 57.3$ respectively. The duration of being diabetic for patients (+10 years) in the study and control groups was $77.1 \% \& 45.7 \%$ respectively. $91.4 \%$ $\& 82.9 \%$ respectively of patients in the study and control groups were treated with insulin injection. $57.1 \%$ and $54.3 \%$ respectively of patients the study and control groups had irregular follow up (Table 2).

The third part of our results was concerned with knowledge of DM among diabetic patients in the study and control groups before the intervention. There was no statistical significant difference between the study group and the control group about knowledge of DM among diabetic patients before the intervention where $91.4 \% \quad \& 100.0 \%$ respectively had unsatisfactory knowledge but there was statistical significant difference between the study group and the control group for knowledge about wound risks $68.6 \%$ \& $37.1 \%$ respectively (Table 3 ).

The fourth part of our results was concerned with knowledge of DM among diabetic patients in the study and control groups after the intervention; indicated that there was statistical significant difference between the study group and the control group after the intervention regarding knowledge of DM among diabetic patients as $82.9 \%$ of patients in the study group had satisfactory knowledge about diabetes and diabetic foot care. On the other hand $91.4 \%$ of patients in the control group had unsatisfactory knowledge about diabetes and diabetic foot care (Table 4).

The fifth part of our results was concerned with Practices related to DM among diabetic patients in the study and control groups before the intervention. It showed that, there was no statistical significant difference between the study group and the control group before the intervention regarding practices related to DM.57.1\% of patients in the study group had inadequate practices related to diabetes mellitus, $71.4 \%$ of patients in the control group had inadequate practices related to diabetes mellitus (Table 5).

The sixth parts of our results was concerned with practices related to DM among diabetic patients in the study and control groups after the intervention. It demonstrated that, there was statistical significant difference between the study group and the control group after the intervention regarding Practices related to DM. On one hand, all of patients in the study group had adequate practices related to DM after the intervention. On the other hand, $62.9 \%$ of patients in the control group had inadequate practices related to DM. There was statistical significant difference between the study group and the control group in action in hypoglycemia. $77.1 \%$ of patients in the study group carry DM card after the intervention but the control group not who had no intervention. There was statistical significant difference between the study group and the control group after the intervention regarding personal care (Regular personal hygiene, Eye care, Visit ophthalmologist, Mouth care, Bathing frequently) with $\mathrm{P}$ value $<0.001 *$ (Table 6).

The seventh part of our results demonstrated that there was statistical significant difference between patients in the study group before and after the intervention as $91.4 \%$ of patients in the study group had unsatisfactory knowledge before the intervention while $17.1 \%$ of them had unsatisfactory knowledge after the intervention with $\mathrm{p}$ value $\left(<0.001^{*}\right)$. There was statistical significant difference between patients in the study group before and after the intervention regarding to total practice as $57.1 \%$ of patients had inadequate practice before the intervention while all of them had adequate practice after the intervention. There was statistical significant difference between patients in the study group before and after the intervention in total foot care as $74.3 \%$ 
of them had inadequate foot care before the care after the intervention (Tables 7,8,9,10).

intervention while all of them had adequate foot

Table (1): Demographic characteristics of diabetic patients in the study and control groups

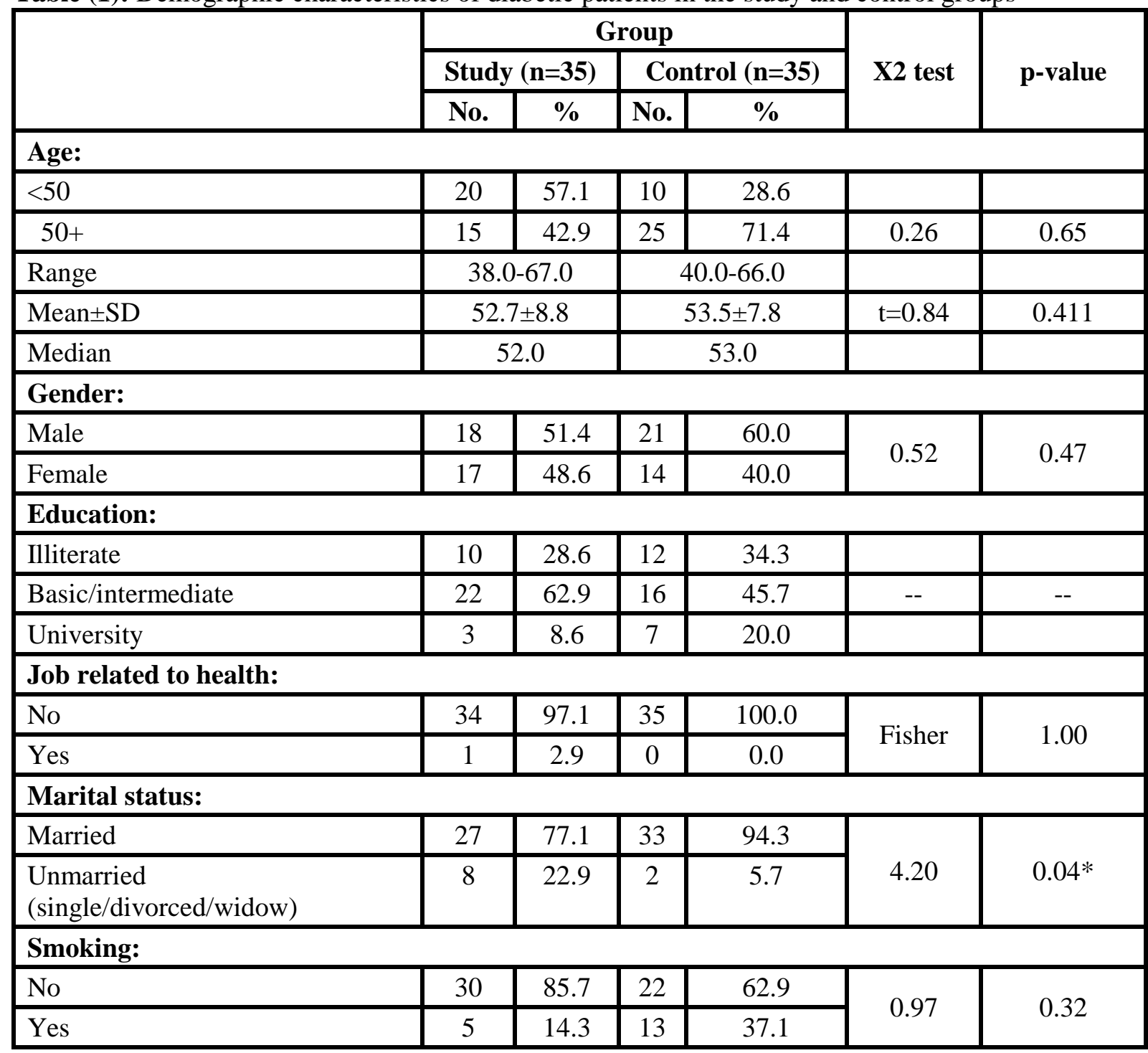

(*) Statistically significant at $\mathbf{p}<0.05$

(--) Test result not valid 
Table (2): History of diabetes (DM) onset and management among diabetic patients in the study and control groups

\begin{tabular}{|c|c|c|c|c|c|c|}
\hline & \multicolumn{4}{|c|}{ Group } & \multirow{3}{*}{$\mathrm{X}^{2}$ test } & \multirow{3}{*}{ p-value } \\
\hline & \multicolumn{2}{|c|}{ Study $(n=35)$} & \multicolumn{2}{|c|}{ Control $(n=35)$} & & \\
\hline & No. & $\%$ & No. & $\%$ & & \\
\hline \multicolumn{7}{|c|}{ Duration of DM (years) } \\
\hline$<10$ & 8 & 22.9 & 19 & 54.3 & & \\
\hline $10+$ & 27 & 77.1 & 16 & 45.7 & 7.30 & $0.007^{*}$ \\
\hline Range & \multicolumn{2}{|c|}{$\frac{1}{5.0-22.0}$} & \multicolumn{2}{|c|}{$2.0-23.0$} & & \\
\hline Mean \pm SD & \multicolumn{2}{|c|}{$12.9 \pm 4.9$} & \multicolumn{2}{|c|}{$9.7 \pm 4.9$} & $\mathrm{t}=8.02$ & $0.005^{*}$ \\
\hline Median & \multicolumn{2}{|c|}{12.0} & \multicolumn{2}{|c|}{8.0} & & \\
\hline \multicolumn{7}{|c|}{ Random blood sugar: } \\
\hline$<140$ & 13 & 37.1 & 14 & 40.0 & & \\
\hline $140+$ & 22 & 62.9 & 21 & 60.0 & 0.06 & 0.81 \\
\hline Range & \multicolumn{2}{|c|}{$110.0-249.0$} & \multicolumn{2}{|c|}{$103-311.0$} & & \\
\hline Mean \pm SD & \multicolumn{2}{|c|}{$157.9 \pm 41.0$} & \multicolumn{2}{|c|}{$167.9 \pm 57.3$} & $\mathrm{t}=0.12$ & 0.73 \\
\hline Median & \multicolumn{2}{|c|}{145.0} & \multicolumn{2}{|c|}{160.0} & & \\
\hline \multicolumn{7}{|l|}{ Treatment: } \\
\hline Insulin & 32 & 91.4 & 29 & 82.9 & \multirow{2}{*}{ Fisher } & \multirow{2}{*}{0.48} \\
\hline Insulin + oral & 3 & 8.6 & 6 & 17.1 & & \\
\hline \multicolumn{7}{|l|}{ Follow-up: } \\
\hline Irregular & 20 & 57.1 & 19 & 54.3 & \multirow{2}{*}{0.06} & \multirow{2}{*}{0.81} \\
\hline Regular & 15 & $\overline{42.9}$ & 16 & $\overline{45.7}$ & & \\
\hline
\end{tabular}

(*) Statistically significant at $\mathbf{p}<0.05$

Table (3): Knowledge of DM among diabetic patients in the study and control groups before the intervention

\begin{tabular}{|c|c|c|c|c|c|c|}
\hline \multirow{3}{*}{$\begin{array}{c}\text { Satisfactory }(50 \%+) \text { knowledge } \\
\text { of DM }\end{array}$} & \multicolumn{4}{|c|}{ Group } & \multirow{3}{*}{$\mathrm{X}^{2}$ test } & \multirow{3}{*}{$\begin{array}{c}\text { p- } \\
\text { value }\end{array}$} \\
\hline & \multicolumn{2}{|c|}{ Study $(n=35)$} & \multicolumn{2}{|c|}{ Control $(n=35)$} & & \\
\hline & No. & $\%$ & No. & $\%$ & & \\
\hline Definition & 7 & 20.0 & 3 & 8.6 & 1.87 & 0.17 \\
\hline Causes & 9 & 25.7 & 5 & 14.3 & 1.43 & 0.23 \\
\hline Symptoms & 11 & 31.4 & 11 & 31.4 & 0.00 & 1.00 \\
\hline Complications & 2 & 5.7 & 6 & 17.1 & Fisher & 0.26 \\
\hline Protection & 8 & 22.9 & 5 & 14.3 & 0.85 & 0.36 \\
\hline Hypoglycemia manifestations & 1 & 2.9 & 0 & 0.0 & Fisher & 1.00 \\
\hline Hypoglycemia causes & 16 & 45.7 & 15 & 42.9 & 0.06 & 0.81 \\
\hline Proper diet & 0 & 0.0 & $\overline{0}$ & 0.0 & 0.00 & 1.00 \\
\hline No. of meals & 0 & 0.0 & 0 & 0.0 & 0.00 & 1.00 \\
\hline \multicolumn{7}{|l|}{ Foot care: } \\
\hline Importance & 1 & 2.9 & 0 & 0.0 & Fisher & 1.00 \\
\hline Methods & 4 & 11.4 & 0 & 0.0 & Fisher & 0.11 \\
\hline Wound risks & 24 & 68.6 & 13 & 37.1 & 6.94 & $0.008 *$ \\
\hline Delayed wound healing & 4 & 11.4 & 6 & 17.1 & 0.47 & 0.49 \\
\hline Trimming nails & 16 & 45.7 & 15 & 42.9 & 0.06 & 0.81 \\
\hline \multicolumn{7}{|l|}{ Total knowledge: } \\
\hline Satisfactory & 3 & 8.6 & 0 & 0.0 & & \\
\hline Unsatisfactory & 32 & 91.4 & 35 & 100.0 & Fisher & 0.24 \\
\hline
\end{tabular}

(*) Statistically significant at $\mathbf{p}<0.05$

Abdelhamid et al., Afro-Egypt J Infect Endem Dis 2019; 9(1): 46-57

https://aeji.journals.ekb.eg/

http://mis.zu.edu.eg/ajied/home.aspx 
Table (4): Knowledge of DM among diabetic patients in the study and control groups after the intervention

\begin{tabular}{|c|c|c|c|c|c|c|}
\hline \multirow{3}{*}{$\begin{array}{c}\text { Satisfactory }(50 \%+) \text { knowledge } \\
\text { of DM }\end{array}$} & \multicolumn{4}{|c|}{ Group } & \multirow{3}{*}{$\mathrm{X}^{2}$ test } & \multirow{3}{*}{ p-value } \\
\hline & \multicolumn{2}{|c|}{ Study $(n=35)$} & \multicolumn{2}{|c|}{ Control $(n=35)$} & & \\
\hline & No. & $\%$ & No. & $\%$ & & \\
\hline Definition & 31 & 88.6 & 19 & 54.3 & 10.08 & $0.001 *$ \\
\hline Causes & 25 & 71.4 & 5 & 14.3 & 23.33 & $<0.001 *$ \\
\hline Symptoms & 21 & 60.0 & 18 & 51.4 & 0.52 & 0.47 \\
\hline Complications & 23 & 65.7 & 10 & 28.6 & 9.69 & $0.002 *$ \\
\hline Protection & 30 & 85.7 & 24 & 68.6 & 2.92 & 0.09 \\
\hline Hypoglycemia manifestations & 14 & 40.0 & 4 & 11.4 & 7.48 & $0.006^{*}$ \\
\hline Hypoglycemia causes & 16 & 45.7 & 15 & 42.9 & 0.06 & 0.81 \\
\hline Proper diet & 10 & 28.6 & 1 & 2.9 & 8.74 & $0.003 *$ \\
\hline No. of meals & 35 & 100.0 & 19 & 54.3 & 20.74 & $<0.001^{*}$ \\
\hline \multicolumn{7}{|l|}{ Foot care: } \\
\hline Importance & 11 & 31.4 & 2 & 5.7 & 7.65 & $0.006^{*}$ \\
\hline Methods & 23 & 65.7 & 10 & 28.6 & 9.69 & $0.002 *$ \\
\hline Wound risks & 26 & 74.3 & 21 & 60.0 & 1.62 & 0.20 \\
\hline Delayed wound healing & 9 & 25.7 & 9 & 25.7 & 0.00 & 1.00 \\
\hline Trimming nails & $\overline{19}$ & 54.3 & 6 & 17.1 & 10.52 & $0.001 *$ \\
\hline \multicolumn{7}{|l|}{ Total knowledge: } \\
\hline Satisfactory & 29 & 82.9 & 14 & 40.0 & \multirow{2}{*}{13.57} & \multirow{2}{*}{$<0.001 *$} \\
\hline Unsatisfactory & 6 & 17.1 & 21 & 60.0 & & \\
\hline
\end{tabular}

(*) Statistically significant at $\mathbf{p}<0.05$

Table (5): Practices related to DM among diabetic patients in the study and control groups before the intervention

\begin{tabular}{|c|c|c|c|c|c|c|}
\hline \multirow{3}{*}{$\begin{array}{c}\text { Adequate }(60 \%+) \\
\text { Practice }\end{array}$} & \multicolumn{4}{|c|}{ Group } & \multirow{3}{*}{$X^{2}$ test } & \multirow{3}{*}{ p-value } \\
\hline & \multicolumn{2}{|c|}{ Study $(n=35)$} & \multicolumn{2}{|c|}{ Control $(n=35)$} & & \\
\hline & No. & $\%$ & No. & $\%$ & & \\
\hline Action in hypoglycemia & 9 & 25.7 & 15 & 42.9 & 2.28 & 0.13 \\
\hline Carry DM card & 0 & 0.0 & 0 & 0.0 & 0.00 & 1.00 \\
\hline \multicolumn{7}{|l|}{ Treatment: } \\
\hline On time & 33 & 94.3 & 34 & 97.1 & Fisher & 1.00 \\
\hline Conditions for change & 28 & 80.0 & 16 & 45.7 & 8.81 & $0.003 *$ \\
\hline \multicolumn{7}{|l|}{ Personal care: } \\
\hline Regular personal hygiene & 23 & 65.7 & 17 & 48.6 & 2.10 & 0.15 \\
\hline Eye care & 23 & 65.7 & 17 & 48.6 & 2.10 & 0.15 \\
\hline Visit ophthalmologist & 12 & 34.3 & 4 & 11.4 & 5.19 & $0.02 *$ \\
\hline Mouth care & 9 & 25.7 & 4 & 11.4 & 2.36 & 0.12 \\
\hline Visit dentist & 5 & 14.3 & 5 & 14.3 & 0.00 & 1.00 \\
\hline Bathing frequently & 23 & 65.7 & 17 & 48.6 & 2.10 & 0.15 \\
\hline \multicolumn{7}{|l|}{ Diet: } \\
\hline Follow regimen & 33 & 94.3 & 16 & 45.7 & 19.66 & $<0.001 *$ \\
\hline Regimen since diagnosis & 23 & 65.7 & 11 & 31.4 & 8.24 & $0.004 *$ \\
\hline \multicolumn{7}{|l|}{ Physical activity: } \\
\hline Practice exercise & 11 & 31.4 & 11 & 31.4 & 0.00 & 1.00 \\
\hline Suitable type & 11 & 31.4 & 11 & 31.4 & 0.00 & 1.00 \\
\hline Regular & 3 & 8.6 & 9 & 25.7 & -- & -- \\
\hline \multicolumn{7}{|l|}{ Total practice: } \\
\hline Adequate & 15 & 42.9 & 10 & 28.6 & \multirow{2}{*}{1.56} & \multirow{2}{*}{0.21} \\
\hline Inadequate & 20 & 57.1 & 25 & 71.4 & & \\
\hline
\end{tabular}

(*) Statistically significant at $\mathbf{p}<0.05$

(--) Test result not valid

Abdelhamid et al., Afro-Egypt J Infect Endem Dis 2019; 9(1):46-57

https://aeji.journals.ekb.eg/

http://mis.zu.edu.eg/ajied/home.aspx 
Table (6): Practices related to DM among diabetic patients in the study and control groups after the intervention

\begin{tabular}{|c|c|c|c|c|c|c|}
\hline \multirow{3}{*}{$\begin{array}{c}\text { Adequate }(60 \%+) \\
\text { Practice }\end{array}$} & \multicolumn{4}{|c|}{ Group } & \multirow{3}{*}{$\mathrm{X}^{2}$ test } & \multirow{3}{*}{ p-value } \\
\hline & \multicolumn{2}{|c|}{ Study $(n=35)$} & \multicolumn{2}{|c|}{ Control $(n=35)$} & & \\
\hline & No. & $\%$ & No. & $\%$ & & \\
\hline Action in hypoglycemia & 31 & 88.6 & 19 & 54.3 & 10.08 & $0.001 *$ \\
\hline Carry DM card & 27 & 77.1 & 0 & 0.0 & 58.95 & $<0.001^{*}$ \\
\hline \multicolumn{7}{|l|}{ Treatment: } \\
\hline On time & 34 & 97.1 & 35 & 100.0 & Fisher & 1.00 \\
\hline Conditions for change & 35 & 100.0 & 20 & 57.1 & 19.09 & $<0.001^{*}$ \\
\hline \multicolumn{7}{|l|}{ Personal care: } \\
\hline Regular personal hygiene & 35 & 100.0 & 24 & 68.6 & 13.05 & $<0.001^{*}$ \\
\hline Eye care & 35 & 100.0 & 21 & 60.0 & 17.50 & $<0.001^{*}$ \\
\hline Visit ophthalmologist & 19 & 54.3 & 5 & 14.3 & 12.43 & $<0.001^{*}$ \\
\hline Mouth care & 34 & 97.1 & 13 & 37.1 & 28.56 & $<0.001^{*}$ \\
\hline Visit dentist & 9 & 25.7 & 4 & 11.4 & 2.36 & 0.12 \\
\hline Bathing frequently & 34 & 97.1 & 17 & 48.6 & 20.88 & $<0.001^{*}$ \\
\hline \multicolumn{7}{|l|}{ Diet: } \\
\hline Follow regimen & 35 & 100.0 & 17 & 48.6 & 24.23 & $<0.001^{*}$ \\
\hline Regimen since diagnosis & 23 & 65.7 & 12 & 34.3 & 6.91 & $0.009^{*}$ \\
\hline \multicolumn{7}{|l|}{ Physical activity: } \\
\hline Practice exercise & 18 & 51.4 & 12 & 34.3 & 2.10 & 0.15 \\
\hline Suitable type & 17 & 48.6 & 12 & 34.3 & 1.47 & 0.23 \\
\hline Regular & 7 & 20.0 & 9 & 25.7 & -- & - \\
\hline \multicolumn{7}{|l|}{ Total practice: } \\
\hline Adequate & 35 & 100.0 & 13 & 37.1 & & \\
\hline Inadequate & 0 & 0.0 & 22 & 62.9 & 32.08 & $<0.001^{*}$ \\
\hline
\end{tabular}

(*) Statistically significant at $\mathbf{p}<0.05$

(--) Test result not valid

Table (7): Knowledge, practice, and foot care diabetic patients in the study group before and after the intervention

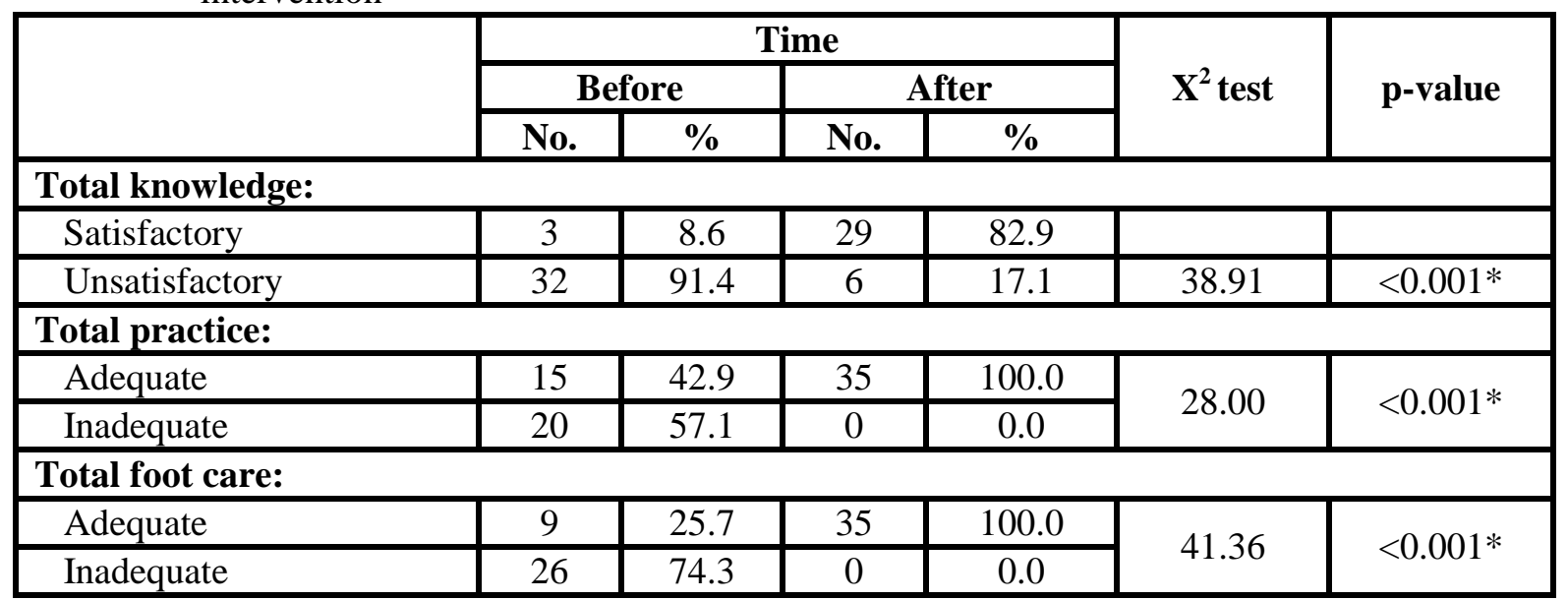


Table (8): Relations between patients' knowledge, practice, and foot care (total pre + post of the sample) $\mathrm{N}=140$

\begin{tabular}{|l|c|c|c|c|c|c|}
\hline \multirow{2}{*}{} & \multicolumn{9}{|c|}{ Knowledge } & \multirow{2}{*}{$\mathbf{X}^{2}$ test } & \multirow{2}{*}{ p-value } \\
\cline { 2 - 5 } & \multicolumn{2}{|c|}{ Satisfactory } & \multicolumn{2}{c|}{ Unsatisfactory } & \\
\cline { 2 - 5 } & No. & \% & No. & \% & & \\
\hline Total practice: & 39 & 53.4 & 34 & 46.6 & & \\
\hline Adequate & 7 & 10.4 & 60 & 89.6 & 29.25 & $<0.001^{*}$ \\
\hline Inadequate & 36 & 59.0 & 25 & 41.0 & & \\
\hline Total foot care: & 10 & 12.7 & 69 & 87.3 & 33.53 & $<0.001^{*}$ \\
\hline Adequate &
\end{tabular}

(*) Statistically significant at $\mathbf{p}<0.05$

Table (9): Best fitting multiple linear regression model for the knowledge score

\begin{tabular}{|l|c|c|c|c|c|c|c|}
\hline \multirow{2}{*}{} & \multicolumn{2}{|c|}{$\begin{array}{c}\text { Unstandardized } \\
\text { Coefficients }\end{array}$} & \multirow{2}{*}{$\begin{array}{c}\text { Standardized } \\
\text { Coefficients }\end{array}$} & \multirow{2}{*}{ t-test } & \multirow{2}{*}{ p-value } & \multicolumn{2}{|c|}{$\begin{array}{c}\text { 95\% Confidence } \\
\text { Interval for B }\end{array}$} \\
\cline { 2 - 5 } & B & Std. Error & & & & Lower & Upper \\
\hline Constant & 3.66 & 1.13 & & 3.244 & 0.001 & 1.43 & 5.88 \\
\hline Intervention & 3.51 & 0.34 & 0.63 & 10.291 & $<0.001$ & 2.84 & 4.19 \\
\hline Female gender & -1.02 & 0.35 & -0.18 & 2.962 & 0.004 & -1.71 & -0.34 \\
\hline Age & -0.06 & 0.02 & -0.23 & 3.765 & $<0.001$ & -0.09 & -0.03 \\
\hline
\end{tabular}

r-square $=0.47 \quad$ Model ANOVA: $F=42.23, p<0.001$

Variables entered and excluded: education, job, DM duration, RBS, FU, group

Table (10): Best fitting multiple linear regression model for the practice score

\begin{tabular}{|l|c|c|c|c|c|c|c|}
\hline \multirow{2}{*}{} & \multicolumn{2}{|c|}{$\begin{array}{c}\text { Unstandardized } \\
\text { Coefficients }\end{array}$} & \multirow{2}{*}{$\begin{array}{c}\text { Standardized } \\
\text { Coefficients }\end{array}$} & \multirow{2}{*}{ t-test } & p-value & \multicolumn{2}{|c|}{$\begin{array}{c}\text { 95\% Confidence } \\
\text { Interval for B }\end{array}$} \\
\cline { 2 - 6 } & B & Std. Error & & & & Lower & Upper \\
\hline Constant & 2.03 & 6.35 & & 0.320 & 0.749 & -10.52 & 14.59 \\
\hline Intervention & 7.82 & 4.08 & 0.15 & 1.918 & 0.057 & -0.24 & 15.89 \\
\hline Education & 9.77 & 1.68 & 0.36 & 5.833 & $<0.001$ & 6.46 & 13.08 \\
\hline Study group & 26.24 & 3.20 & 0.52 & 8.191 & $<0.001$ & 19.91 & 32.58 \\
\hline Knowledge score & 1.51 & 0.75 & 0.17 & 2.018 & 0.046 & 0.03 & 3.00 \\
\hline
\end{tabular}

r-square $=0.47 \quad$ Model ANOVA: $F=32.22, p<0.001$

Variables entered and excluded: age, gender, job, DM duration, RBS, FU

\section{DISCUSSION}

Diabetes Mellitus (DM) is metabolic disorder characterized by chronic hyperglycemia and trouble in metabolism of carbohydrates, protein and fat as a result of defect in insulin secretion, insulin action or both, DM is highly prevalent worldwide, in 1980; 108 million adults $(4.7 \%)$ were suffering from DM, this number increased to 422 million (8.5\%) in 2014. In 2015 a study was published by International Diabetes Federation, there is one adult suffering from diabetes in every eleven and one undiagnosed diabetic patient in every two patients [6]. Education programmes for patients with diabetes and their families should be provided to enhance community awareness of DFD and emphasize the importance of optimal diabetes control to prevent complications in

Abdelhamid et al., Afro-Egypt J Infect Endem Dis 2019; 9(1):46-57

https://aeji.journals.ekb.eg/

http://mis.zu.edu.eg/ajied/home.aspx 
general and regular foot self-care practices to prevent foot ulcers in particular [7]. One of the noticeable findings of the study was that more than half of the patients included in the study were male. This finding is supported by Mohsen and Shehata [8] who published their study about foot self care: knowledge, practice and barriers among diabetic patients in Menofia University found that more than half of their study were male but this finding is in disagreement with Mohamed [9], who was studying factors contributing to diabetic patients foot ulcers and concepts of prevention as perceived by medical and surgical nurses and reported that the majority of the study were females. This result is due to men with diabetes are at increased risk of foot ulcers or amputation compared with women with diabetes.

The present study revealed that the mean age of patients in the study group and the control group was (52\&53 years respectively). This finding is in agreement with Bohtera [10] who was studying our experience in diabetic foot management stated that the mean age of the patients presented with diabetic foot in the study was 57 years. This result is due to diabetic foot problems are unusual in patients $<40$ years of age. They increase with age $>40$ years, and occur most commonly in those aged 50 years and older. However, duration and control of diabetes are greater predictors of diabetic foot problems than chronological age [11].

The results showed that more than two fifth of the patients included in the study group and the control group had basic education. This finding is consistent with Soliman [12], who was studying factors affecting healing of diabetic foot ulcer in Ain Shams University found that about half of the patients in the study was secondary educated and in agreement with Phillipo et al. [13] who was studying surgical management of diabetic foot ulcers: A Tanzanian university teaching hospital experience found that most of the studied sample had either primary or no formal education. The result of the present study may be due to low level of education lead to certain factors, such as barefoot walking, low socioeconomic status and late presentation by patients to hospital or clinic.

Concerning duration of being diabetic, the present study revealed that, the duration of being diabetic for Studied group about three quarters of them was $\geq 10$ years with mean 13 years. This result agree with the result of Soliman [12] who found that more than half of patients in her study was ranged between (11-20) and in accordance with Abd-Elrazak [14] who was studying compliance of diabetic patients toward different therapeutic regimen in Zagazig University who reported about one half of patients had diabetes of more than five years, and this finding might be due to the chronicity of the disease. Glucose levels are vital signs of individuals with diabetes. It is important to consistently maintain blood sugar levels within a normal range to avoid short and long term complications. The current study revealed that the blood glucose level was $+140 \mathrm{mg} \backslash \mathrm{dl}$ for more than half of patients in the study group and the control group. This finding disagrees with Kaewloet [15] who was studying the correlations between affecting factors and healing rate in diabetic foot ulcers found that more than half of the sample in the study had blood glucose level of $\geq 200 \mathrm{mgldl}$.

Concerning diabetes treatment, the present study showed that the majority of patients in the study group and control group were treated with insulin injection. This finding is consistent with Soliman [12] who found that the majority of patients in the study were treated with insulin injection and in agreement with Abd-Elrazak [14] who reported that more than half of diabetic patients were depending on insulin to control their blood glucose levels. According to the finding of the present study, there was no statistical significant difference between the study group and the control group about Knowledge of DM among diabetic patients before the intervention where majority of patients in both group had unsatisfactory knowledg. This result agree with Nagarathnam, et al. [16] who was studying assessment of knowledge on foot care among diabetic patients attending tertiary care hospital in AP found that only $15 \%$ of the study sample had adequate knowledge on foot care and near the result of Fareed [17] who was studying effect of education on knowledge, self management behaviors and self efficacy of patient with type 11 diabetes mellitus in Helwan University illustrated that more than three fourth of studied sample had poor knowledge score for diabetes. The results of the present study approved that Diabetic patients who received the self management support program about signs, symptoms as well as the management of hypoglycemia showed significant improvement in their knowledge ; this finding is supported by Abdel-Galeal [18] \& Abdel-Hady [19] who stated that diabetics knowledge about hypoglycemia and hyperglycemia were inadequate 
in pre-test and increased significantly in posttest. Also American diabetic Association (20) recommended that it is very important that the diabetic patients must be able to recognize the signs and symptoms of early hypo or hyperglycemia to be able to take life saving measures. On the other hand, the present study revealed that, majority of patients in the study and control groups take drug on time. This may be due to they want to control blood glucose level to prevent recurrence of diabetic foot. Also all of patients in the study group change dose according to blood glucose level, delay eating and general condition in the post-test and more than half of patients in the control group. This results is in agreement with Abd-Elrazak [14] who found that the majority of the patients were good compliant with medication use and in consistent with Mokhtar [21] who found that two thirds of the patient with foot problem comply with medication dose and one third of patients with foot problems changes medication dose according to general condition and present of stress.

As regards to Practices related to DM among diabetic patients in the study and control groups before the intervention there was no statistical significant difference between the study group and the control group before the intervention regarding Practices related to DM as more than half of patients in the study group had inadequate practices related to diabetes mellitus in the pre test, but after self management support program there was a highly significant difference detected between control and studied groups. Regarding to Action in hypoglycemia, carry DM card more than three quarters of patients in the studied group know how to act in occurrence of hypoglycemia, about three quarters of them carry diabetic card done by the researcher. Regarding to the personal hygiene the present study results have shown that, before implementation of the program, only $48.6 \%$ of control group and $65.7 \%$ of the studied group has mentioned they takes bath frequently, but after implementation of the program majority of the studied group take bath frequently.

American Diabetic Association [20] reported that the diabetic patient should brush their teeth at least twice a day, and should see the dentist every six month. In this respect one quarter of studied group brush their teeth daily, and less than quarter of control group brush their teeth daily and the majority of both studied \& control group not visit dentist routinely unless they had teeth problems. After implementation of the program, there was a statistically significant improvement in dental care among the study group.

On summary, the results of this study support the hypothesis that diabetic foot care behaviors of patients who received self management support program were higher than that in the control group. There was a significant improvement in knowledge, self-reported practices and foot care behaviors in posttest in the study group.

\section{CONCLUSION}

The self management support program showed an improvement in patients' knowledge which reflected an improvement on their self reported practices and diabetic foot care behaviors in post phase.

\section{RECOMMENDATION}

- Apply nursing intervention programs regarding importance of foot care and to impart knowledge on foot care

- Training courses about diabetic foot care and handouts about suitable shoes should be available for diabetic foot patients.

\section{Administrative and Ethical considerations:}

An official permission for data collection in Zagazig University Hospitals was obtained from the out-patient administrative personnel by the submission of a formal letter from the dean of the faculty of Nursing to obtain the approval to conduct the study. Letter was issued to them from the Faculty of Nursing, Zagazig University explaining the aim of the study to obtain their permission and help.

\section{Funding:}

None.

Conflicts of interest:

There are no conflicts of interest.

\section{REFERENCES}

1. Mardanian Dehkordi L, Abdoli S. Diabetes selfmanagement education; experience of people with diabetes. J Caring Sci 2017; 6 (2): 43-55. doi:10.15171/jcs.2017.011.

2. American Diabetes Association. Diagnosis and Classification of Diabetes Mellitus care. diabetes journals. org volume 36, supplement 1, January 2013 retrieved from http://care.diabetesjournals. org//accessed on January 17, 2014. 
3. Bartolo P, Mizzi S, Formosa C. An evaluation of foot care ehavior in individuals with type 2 diabetes living in Malta. Journal of Diabetes Nursing 17: 72-77 2013.

4. Edo EA, Edo GO, Uzeani IU. Risk factors, ulcer grade and management outcome of diabetic foot ulcers in a tropical tertiary care hospital. Niger Med J; 54:59-632013.

5. International Diabetes Federation. IDF Diabetes Atlas, 7th ed. Watermael-Boitsfort, Belgium. International Diabetes Federation, 2015. Pp. 50120.

6. World Health Organization (WHO). Global Report on Diabetes. WHO: Geneva, Switzerland.; Diabetic Foot Awareness among Diabetic Patients, 1290 2016.

7. Al-Busaidi IS, Coppell KJ, Abdulhadi N.: Care of Patients with Diabetic Foot Disease in Oman. Sultan Qaboos University Med J, August 2016, Vol. 16, Iss. 3, pp. e270-276, Epub. 19 Aug 16 2016.

8. Mohsen MM and Shehata AE. Foot Self Care: Knowledge, Practice And Barriers Among Diabetic Patients. Published paper in Zagazig Nursing Journal, Faculty of Nursing, Menofia University; 2014.

9. Mohamed, SA. Factors contributing to diabetic patients foot ulcers and concepts of prevention as perceived by medical and surgical nurses. The New Egyptian Journal of Medicine, 38(3), 192(2008)

10. Bohtera, F., M., M.: Our experience in diabetic foot management. The New Egyptian Journal of Medicine, 2011; 44(1),49.

11. Abdelhamid FM. Factors affecting wound healing and needs among patients with diabetic foot ulcer.master thesis. Faculty of Nursing. Zagazig University, 2015.

12. Soliman AM. Factors Affecting Healing of Diabetic Foot Ulcer. Faculty of nursing. Ainshams University. Master Thesis, 2012; P:24.

13. Phillipo LC, Joseph BM, Ramesh MD, Rodrick K, Hyasinta J, Mabula DM, Johannes BK, Nkinda M and Japhet MG. Surgical management of Diabetic foot ulcers: A Tanzanian university teaching hospital experience BMC Research Notes 24 September 2011 Available at http:// www.biomedcentral.com/1756-0500/4/365 accessed on 22 Mach 2015.

14. Abd-Elrazak BG. Compliance of diabetic patients toward different therapeutic regimen, Unpublished Master thesis, Faculty of Nursing, Zagazig University; 2009.

15. Kaewloet N. The correlations between affecting factors and healing rate in diabetic foot ulcers. Retrived From: http://mulinet 10.li.mahidol.ac. th14737289.pdf, 2008; Accessed on 3July 2010.

16. Nagarathnam M, Bhavani KL, Deepthi S. Assessment of Knowledge on Foot Care among Diabetic Patients Attending Tertiary Care Hospital In AP. JSWCR; 2014, 7(1): 29-32.

17. Fareed M. Effect of education on knowledge, self management behaviors and self efficacy of patient with type 11 diabetes mellitus. The 4 the International Scientific Nursing Conference, Faculty of nursing, Helwan University in collaboration with Kennesaw University (KSU), USA Innovations in Nursing Researches, Education and Practice; 23-24 April 2012:p 56

18. Abdel-Glaeal. Implementation of an educational program for diabetic children and their mothers attending the diabetic clinical. Unpublished doctor thesis, Faculty of Nursing, Benha University, 2012.

19. Abdel-Hady EM. A comparative study between two methods of health education to control diabetes among Egyptian females patients (Disscrtation) faculty of nursing .Cairo University, 2013.

20. American Diabetes Association,: Diabetes Care, care.diabetesjournals.org volume 36, supplement 1, January 2013 retrieved from http://care.Diabetes journals.org//accessed on January 17, 2014.

21. Mokhtar IM. Diabetic patient suffering from foot problem at Met Ghamer Hospital. Master thesis. Zagazig University, 2011. 